\title{
Infecção por Fusarium graminearum e Fusarium verticillioides em sementes de milho ${ }^{1}$
}

\author{
Dayana Portes Ramos², Rafael Marani Barbosa ${ }^{2}$, \\ Bruno Guilherme Torres Licursi Vieira ${ }^{2}$, Rita de Cássia Panizzi ${ }^{3}$, Roberval Daiton Vieira ${ }^{2}$
}

\begin{abstract}
Fusarium graminearum and Fusarium

verticillioides infection on maize seeds

The previous knowledge of the infection process and pathogens behavior, for evaluating the physiological potential of maize seeds, is essential for decision making on the final destination of lots that can endanger sowing. This research was carried out in order to study the minimum period required for maize seeds contamination by Fusarium graminearum Schwabe and Fusarium verticillioides (Sacc.) Nirenberg, as well as these pathogens influence on seed germination and vigor, by using the cold test. Three maize seeds hybrids, kept in contact with the pathogens for different periods, were evaluated with and without surface disinfection. After determining the most suitable period, new samples were contaminated by $F$. graminearum and $F$. verticillioides, under different infection levels, and subjected to germination tests in sand. The cold test was conducted with healthy and contaminated seeds, at different periods, in a cold chamber. The contact of maize seeds with $F$. graminearum and $F$. verticillioides for 16 hours was enough to cause infection. $F$. graminearum and $F$. verticillioides did not affect the maize seeds germination, however, F. graminearum reduced the vigor of seeds lots.
\end{abstract}

KEY-WORDS: Zea mays L.; seed pathology; cold test.

\section{INTRODUÇÃO}

A semente é o principal insumo agrícola, uma vez que transporta para o campo todo o potencial genético da espécie, e, para que este se expresse, é necessário, dentre outros fatores, que a semente possua elevado potencial fisiológico e ausência de patógenos.

Sementes de milho são susceptíveis a diversos fungos prejudiciais, durante as diferentes fases de produção, principalmente durante o estabelecimento

\section{RESUMO}

O prévio conhecimento do processo de infecção e do comportamento de patógenos, na avaliação do potencial fisiológico de sementes de milho, é essencial para a tomada de decisão sobre o destino de lotes que podem comprometer a semeadura. Objetivou-se, com este trabalho, determinar o período mínimo necessário para a contaminação de sementes de milho por Fusarium graminearum Schwabe e Fusarium verticillioides (Sacc.) Nirenberg, bem como avaliar a influência destes patógenos na germinação e no vigor de sementes, por meio do teste de frio. Foram utilizadas sementes de três híbridos de milho, as quais entraram em contato com os patógenos em diferentes períodos, avaliados com e sem desinfestação superficial. Após a determinação do período adequado, novas amostras foram contaminadas por $F$. graminearum e $F$. verticillioides, sob diferentes níveis de infecção, e submetidas ao teste de germinação em areia. $\mathrm{O}$ teste de frio foi realizado com sementes sadias e contaminadas, em diferentes períodos, em câmara fria. O período de 16 horas de contato das sementes de milho com $F$. graminearum $\mathrm{e}$. verticillioides foi suficiente para a ocorrência de infecção. F. graminearum e $F$. verticillioides não interferiram na germinação de sementes de milho, contudo, F. graminearum reduziu o desempenho dos lotes de sementes.

PALAVRAS-CHAVE: Zea mays L.; patologia de sementes; teste de frio.

da cultura, e estes ocasionam redução na população de plantas e enfraquecimento de plântulas, durante as etapas iniciais de seu desenvolvimento (Cappelini et al. 2005).

Algumas espécies do gênero Fusarium têm sido associadas a doenças do milho, como Fusarium graminearum Schwabe (teleomorfo, Gibberella zeae (Scw.) Petch) e Fusarium verticillioides (Sacc.) Nirenberg (sinônimo, Fusarium moniliforme Sheldon; teleomorfo, Gibberella moniliformes, si-

1. Trabalho recebido em fev./2013 e aceito para publicação em jan./2014 (nº registro: PAT 22694).

2. Universidade Estadual Paulista (Unesp), Faculdade de Ciências Agrárias e Veterinárias, Departamento de Produção Vegetal, Jaboticabal, SP, Brasil.E-mails: pitchagro@yahoo.com.br, rmarani@gmail.com, vieirabgtl@gmail.com, rdvieira@fcav.unesp.br.

3. Universidade Estadual Paulista (Unesp), Faculdade de Ciências Agrárias e Veterinárias, Departamento de Fitossanidade, Jaboticabal, SP, Brasil.E-mail: rpanizzi@fcav.unesp.br. 
nônimo, Gibberella fujikuroi), em todos os estádios de desenvolvimento (Sartori et al. 2004), podendo infectar sementes e plântulas. Desta forma, estes patógenos economicamente importantes para os cereais podem causar perdas substanciais em produtividade e na qualidade de sementes (Broders et al. 2007).

Esses fungos podem sobreviver no solo por meio de estruturas de resistência e, ainda, em estruturas internas das sementes, como o embrião. A diagnose preventiva, antes da semeadura, assim como o tratamento químico de sementes, são medidas que auxiliam no combate a doenças ocasionadas por Fusarium spp. (Costa et al. 2003). No entanto, para que estudos mais aprofundados sejam realizados, é necessário maior conhecimento sobre a biologia e sobrevivência destes fungos, como o período para a contaminação e o desenvolvimento de métodos eficazes de inoculação de sementes.

Estudos mostraram que $F$. verticillioides, inoculado em sementes de milho, não retardou o desenvolvimento das plântulas, e que o crescimento do fungo é dependente do tipo, idade e condições dos tecidos vegetais do hospedeiro (Yates et al. 2005).

Após o ponto de maturidade fisiológica, ou no armazenamento, a presença de micro-organismos patogênicos reduz o potencial fisiológico e a qualidade sanitária das sementes em maior velocidade (Barbosa et al. 2013). Esta presença também está associada ao decréscimo do poder germinativo, menor desenvolvimento de plântulas nos seus primeiros estádios de desenvolvimento e transmissão do patógeno para a parte aérea e sistema radicular da planta (Muniz et al. 2004).

O potencial fisiológico de sementes pode ser avaliado, tradicionalmente, pelo teste de germinação, conduzido sob condições adequadas de temperatura, disponibilidade hídrica e oxigênio, e testes de vigor, que avaliam o desempenho de sementes sob condições desfavoráveis de ambiente, como, por exemplo, o teste de frio.

Quando associado à presença de patógenos, o teste de vigor pode ser ainda mais sensível para identificar diferenças sutis no potencial fisiológico, entre lotes com germinação aceitável. Assim, para a realização e padronização desses testes, requerem-se sementes comprovadamente infectadas por patógenos, para que o efeito seja mensurável e passível de ser reproduzido.

Para a cultura do milho, utiliza-se o teste de frio para avaliar o vigor das sementes. O princípio deste teste está relacionado com a exposição das sementes à combinação de baixa temperatura e alta umidade do substrato e aos agentes patogênicos, devido à utilização de terra proveniente de áreas de cultivo da espécie (Woltz et al. 1998, Lovato et al. 2005).

Diante do exposto, objetivou-se, com este trabalho, determinar o período mínimo ideal para a contaminação de sementes de milho por Fusarium verticillioides e Fusarium graminearum, bem como avaliar a influência destes fungos no desempenho de sementes de milho.

\section{MATERIAL E MÉTODOS}

O experimento, dividido em três etapas, foi realizado nos Laboratórios de Patologia de Sementes do Departamento de Fitossanidade e no Laboratório de Análise de Sementes do Departamento de Produção Vegetal da Universidade Estadual Paulista (Unesp), Campus de Jaboticabal (SP), em 2011.

Os fungos $F$. graminearum e $F$. verticillioides foram isolados de sementes de milho com sintomas característicos do patógeno (grãos com alteração na cor, variando do róseo ao marrom escuro, na parte superior). Os fungos foram cultivados em meio de cultura batata-dextrose-ágar (BDA) e conservados em tubos de ensaio contendo óleo mineral. Para a multiplicação do inóculo, foi utilizado o meio de cultura BDA e o fungos foram incubados à temperatura ambiente $\left(20-30^{\circ} \mathrm{C}\right)$, com fotoperíodo de 12 horas. As placas contendo o fungo permaneceram no laboratório, sem controle das condições ambientais, durante 15 dias.

Sementes dos híbridos H8480, H657 e H577 (Dow Agroscience) foram contaminadas com $F$. graminearum e $F$. verticillioides, por meio da deposição destas sobre o micélio dos fungos, de modo que todas as sementes permanecessem em contato com as estruturas. O período de incubação das sementes sobre as colônias dos fungos foi de 0 ; $4 ; 8 ; 16$; e 32 horas. Após estes períodos, as sementes foram submetidas ao teste de sanidade, com e sem desinfestação superficial.

A desinfestação foi realizada por meio da imersão de uma amostra de cada híbrido por período de incubação das sementes em solução de hipoclorito de sódio a $1 \%$, durante 3 minutos. Posteriormente, as sementes foram lavadas com água esterilizada e secas à temperatura ambiente. Após a obtenção dos tratamentos, as amostras foram submetidas ao teste de sanidade. 
O teste de sanidade foi realizado pelo método de papel filtro com congelamento (Limonard 1966). Foram utilizadas 200 sementes por híbrido, distribuídas em placas de Petri de 9,0 cm. Dez sementes foram colocadas equidistantes em cada placa, sobre três folhas de papel filtro previamente umedecido com água destilada, e incubadas, durante 24 horas, a $20 \pm 2^{\circ} \mathrm{C}$. Após este período, as placas foram transferidas para ambiente a $-20^{\circ} \mathrm{C}$, durante 24 horas, e, posteriormente, para câmara de incubação, por mais 5 dias.

As avaliações foram realizadas individualmente, examinando-se as sementes sob microscópio estereoscópico, e os fungos identificados por meio das características morfológicas de suas estruturas. Os resultados foram expressos em percentagem de sementes contaminadas, para cada fungo.

Foi utilizado delineamento experimental inteiramente casualizado e os tratamentos dispostos em esquema fatorial $2 \times 3 \times 5$ (métodos de detecção: com e sem desinfestação superficial $\times$ híbridos de milho $\times$ períodos de exposição das sementes ao fungo), com cinco repetições.

As sementes de milho híbrido permaneceram em contato com estruturas dos fungos durante 16 horas (resultados obtidos na primeira etapa). Desta forma, procedeu-se à composição dos tratamentos, para verificar a influência do nível de infecção das sementes sobre os resultados da germinação, em que sementes infectadas e sementes sadias foram misturadas em diferentes proporções [0 (sementes sadias), 1/5 (uma parte de sementes infectadas/ cinco partes de sementes sadias: $20 \%), 2 / 5(40 \%), 3 / 5(60 \%)$, $4 / 5(80 \%)$ e $5 / 5(100 \%$ de sementes infectadas)] e submetidas ao teste de germinação em areia.

$\mathrm{O}$ teste de germinação em areia foi realizado com quatro repetições de 50 sementes por tratamento, semeadas em areia lavada, em caixas de plástico $(26 \times 16 \times 8,5 \mathrm{~cm})$. A umidade do substrato foi ajustada para $70 \%$ da capacidade de retenção. As caixas foram colocadas em câmara de germinação regulada a $25^{\circ} \mathrm{C}$, as leituras realizadas aos 4 e 7 dias após a instalação do teste e os resultados expressos em percentagem de plântulas normais (Brasil 2009).

Nesse ensaio, utilizou-se delineamento inteiramente casualizado, em esquema fatorial $6 \times 2$ (níveis de infecção $\times$ espécies de fungos), com quatro repetições.

O teste de frio foi realizado separadamente com sementes sadias, contaminadas $\operatorname{com} F$. verticillioides e com $F$. graminearum, utilizando-se, como substrato, uma mistura de $2 / 3$ de areia e $1 / 3$ de terra proveniente de área experimental cultivada com milho. O substrato foi colocado em caixas de plástico $(26 \times 16 \times 8,5 \mathrm{~cm})$ e, posteriormente, realizou-se a semeadura e o ajuste da umidade do substrato para $70 \%$ da capacidade de campo. As caixas foram tampadas e colocadas em câmara fria $\left(10^{\circ} \mathrm{C}\right)$, durante 10 dias, e, diariamente, os materiais correspondentes às parcelas experimentais foram retirados e levados à câmara de germinação regulada a $25^{\circ} \mathrm{C}$. Após cinco dias, procedeu-se à contagem de plântulas normais (Cícero \& Vieira 1994, Barros et al. 1999).

Nesse experimento, foi utilizado o delineamento inteiramente casualizado, em esquema fatorial $10 \times 3$ (10 períodos em câmara fria $\times 3$ situações de infecção: sementes sadias, contaminadas com $F$. verticillioides e com $F$. graminearum, separadamente para cada híbrido), com quatro repetições.

Para os três experimentos, os dados foram submetidos à análise de variância e de regressão polinomial, e aqueles que não obtiveram distribuição normal foram previamente transformados em arc sen $(\mathrm{x} / 100)^{1 / 2}$. Quando necessário, as médias foram comparadas pelo teste Tukey, a 5\% (Banzatto \& Kronka 2006).

\section{RESULTADOS E DISCUSSÃO}

Nas amostras de sementes sem desinfestação, todos os períodos avaliados para contaminação com $F$. graminearum e F. verticillioides foram satisfatórios, pois houve aumento da incidência, em relação à testemunha. Somente os valores de incidência dos fungos para as sementes com desinfestação superficial ajustaram-se a modelos quadráticos (Figura 1). $\mathrm{O}$ contato das estruturas dos fungos com as sementes de milho proporcionou contaminação superficial nas primeiras horas, evidenciada pelas taxas das amostras sem desinfestação superficial. Por outro lado, para colonizar o interior das sementes, ambos os fungos levaram 32 horas.

Estudo semelhante, conduzido com sementes de milho, também apontou que o contato das sementes com F. graminearum, por 32 horas, foi suficiente para a obtenção de sementes infectadas (Galli et al. 2005).

A semente é considerada infestada quando o patógeno está ligado à sua superfície, e infectada quando o patógeno é encontrado dentro de seus tecidos (Galli et al. 2005). A desinfestação super- 

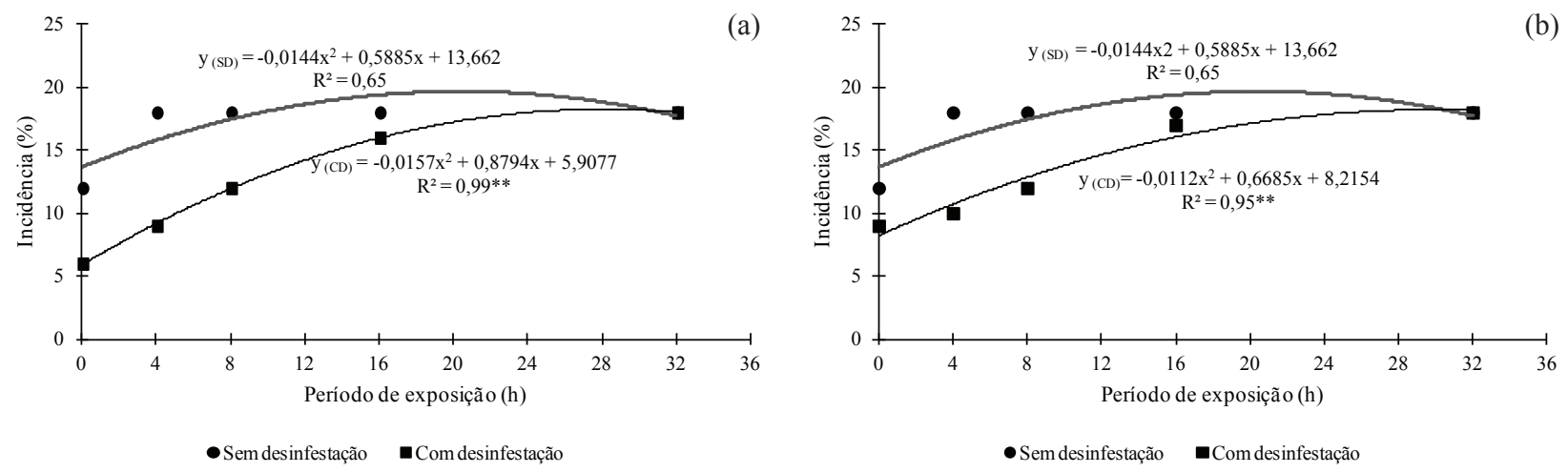

Figura 1. Incidência de Fusarium graminearum (a) e Fusarium verticillioides (b) avaliada pelo teste de sanidade, em função dos períodos de inoculação e desinfestação superficial das sementes (Jaboticabal, SP, 2011). R²: coeficiente de determinação; ** função polinomial significativa a $1 \%$, pelo teste $\mathrm{F}$.

ficial fez com que o inóculo presente no pericarpo das sementes de milho se apresentasse sob menores valores em todos os períodos de incubação, exceto para 32 horas. Portanto, pelo fato de as sementes desinfestadas superficialmente terem apresentado taxas consideráveis de infecção, entende-se que o fungo colonizou os tecidos do embrião e endosperma das sementes de milho.

Em relação ao período de contato das sementes com as estruturas dos fungos, para cada híbrido, os valores ajustaram-se a funções quadráticas (Figura 2). Após 4 horas, as sementes do híbrido H8480 apresentaram as maiores médias para contaminação por $F$. graminearum, e, após 21 horas de exposição, atingiram o valor máximo da função ajustada, com $20 \%$ de incidência. Com o decorrer do período de exposição, os híbridos H657 e H577 levaram 26 horas e 35 horas, respectivamente, para atingir $18 \%$ de incidência (Figura 2a). Por outro lado, após 16 horas de exposição, foram encontrados $19 \%, 17 \%$ e $16 \%$ de incidência, o que pode ser considerado o período suficiente para a obtenção de sementes contaminadas por $F$. graminearum, por estarem, estes valores, próximos ao vértice da função ajustada.

Possivelmente, o híbrido H8480 apresentava problemas por injúria mecânica, facilitando, com isto, a penetração do fungo, pois, em sementes deterioradas, a colonização por fungos fitopatogênicos é facilitada (Cappelini et al. 2005).

Com relação a $F$. verticillioides, o contato das sementes com as estruturas dos fungos proporcionou pico de $18 \%$ de contaminação, após 25,24 e 27 horas, respectivamente para os híbridos H8480, H657 e H577 (Figura 2b). Porém, analogamente a $F$. graminearum, 17 horas de exposição foram suficientes para a obtenção de sementes contaminadas com $F$. verticillioides. Por não haver drásticas dife-
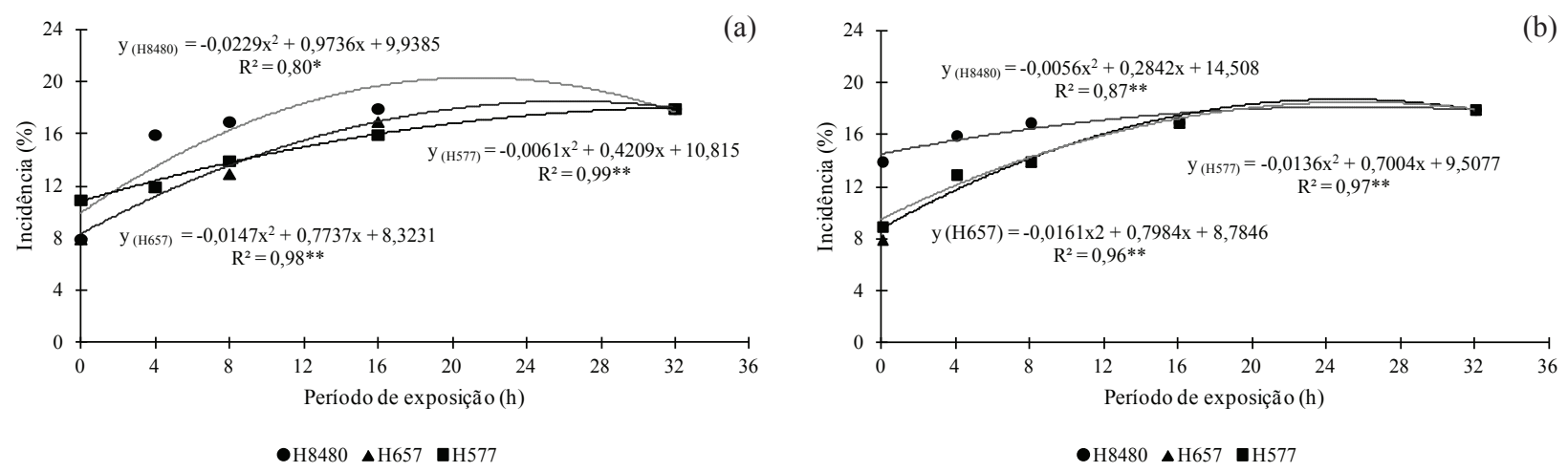

Figura 2. Incidência de Fusarium graminearum (a) e Fusarium verticillioides (b) em sementes de milho híbrido H8480, H657 e H577, inoculadas artificialmente por diferentes períodos (Jaboticabal, SP, 2011). $\mathrm{R}^{2}$ : coeficiente de determinação; ** função polinomial significativa a $1 \%$, pelo teste $\mathrm{F}$. 
renças entre o nível de contaminação, por períodos maiores, e frente à necessidade de se obter resultados com rapidez, o menor período pode ser considerado adequado para a obtenção de sementes contaminadas. Contudo, espera-se que os fungos continuem o seu desenvolvimento e elevem as taxas de incidência.

As sementes de todos os híbridos sem desinfestação superficial apresentaram comportamento semelhante, em relação à incidência de $F$. graminearum e F. verticillioides. Porém, as sementes desinfestadas do híbrido H8480 apresentaram, de maneira geral, maior taxa de incidência nas sementes inoculadas (Tabela 1).

A germinação das sementes dos híbridos H8480 e $\mathrm{H} 577$ não foi comprometida por $F$. graminearum e $F$. verticillioides, mesmo em sementes infectadas sob diferentes níveis de infecção (Figura 3). Os dados não se ajustaram a funções que descreveriam a relação entre o nível de incidência dos fungos e a germinação de sementes dos três híbridos avaliados. Portanto, a presença destes fungos não interferiu na germinação de sementes de milho.

Várias pesquisas demonstraram que esses fungos não afetam a germinação de sementes de milho (Moraes et al. 2003, Cappelini et al. 2005, Henning et al. 2011, Solorzano \& Malvick 2011). Todavia, a redução na germinação de sementes de milho infectadas por $F$. verticillioides é possível, pois este fungo apresenta crescimento rápido e agressivo, e pode causar a morte das sementes antes mesmo da germinação (Antonello et al. 2009).

F. verticillioides é o patógeno mais detectado em sementes de milho e, quando presente, pode interferir no potencial fisiológico, reduzindo o estande de plantas em campo (Albuquerque \& Carvalho 2003).

Tabela 1. Incidência de Fusarium graminearum e Fusarium verticillioides em sementes de milho híbrido H8480, H657 e H577, com ou sem desinfestação superficial (Jaboticabal, SP, 2011).

\begin{tabular}{|c|c|c|c|c|}
\hline \multirow{3}{*}{ Híbridos } & \multicolumn{2}{|c|}{ Fusarium graminearum } & \multicolumn{2}{|c|}{ Fusarium verticillioides } \\
\hline & SD & $\mathrm{CD}$ & SD & $\mathrm{CD}$ \\
\hline & \multicolumn{4}{|c|}{$\%$} \\
\hline H8480 & $17 \mathrm{aA}^{1}$ & $14 \mathrm{aB}$ & $17 \mathrm{aA}$ & $16 \mathrm{aB}$ \\
\hline H657 & $16 \mathrm{aA}$ & $11 \mathrm{bB}$ & $17 \mathrm{aA}$ & $11 \mathrm{cB}$ \\
\hline H577 & $17 \mathrm{aA}$ & $11 \mathrm{bB}$ & $16 \mathrm{aA}$ & $12 \mathrm{bB}$ \\
\hline C.V. $(\%)$ & \multicolumn{2}{|c|}{12,7} & \multicolumn{2}{|c|}{13,2} \\
\hline
\end{tabular}

${ }^{1}$ Médias seguidas pela mesma letra minúscula, nas colunas, e maiúscula, nas linhas, para cada fungo, não diferem significativamente entre si, pelo teste Tukey, a $5 \%$. Médias originais, mas, para efeito estatístico, foram transformadas em $\operatorname{arc} \operatorname{sen}(\mathrm{x} / 100)^{0,5} . \mathrm{SD}=$ sem desinfestação superficial das sementes; $\mathrm{CD}=\mathrm{com}$ desinfestação superficial das sementes.

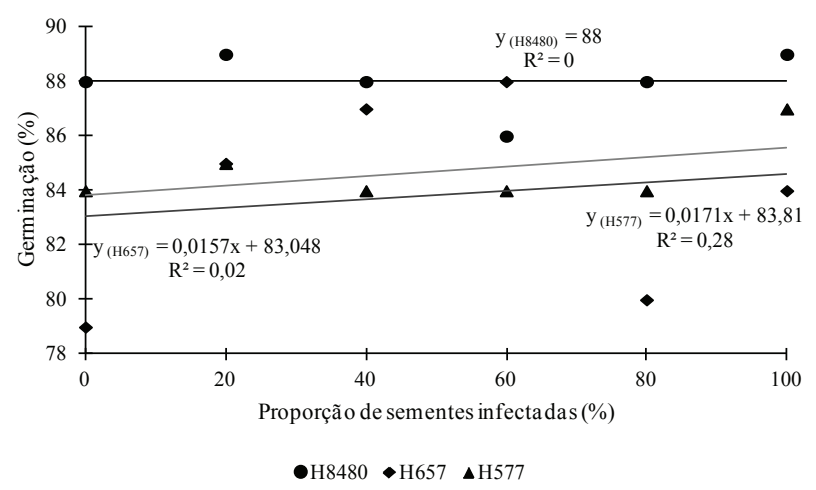

Figura 3. Germinação de sementes de milho híbrido H577, H657 e H8480, com diferentes níveis de infecção artificial por Fusarium graminearum e Fusarium verticillioides (Jaboticabal, SP, 2011). $\mathrm{R}^{2}$ : coeficiente de determinação.

Quando a semeadura ocorre em condições ambientais adequadas, em termos de disponibilidade hídrica, temperatura e preparo do solo, este patógeno não afeta a germinação de sementes de milho. Contudo, na ausência de fatores favoráveis ao estabelecimento da cultura, observaram-se correlações negativas entre a incidência de $F$. verticillioides e o desempenho das sementes, em que o efeito nocivo do fungo foi maior em sementes de baixa qualidade fisiológica (Cappelini et al. 2005).

Em sementes de milho, a germinação não foi reduzida, mas houve redução no vigor das sementes logo após a inoculação em placas contendo ágar colonizado por $F$. graminearum, por 32 horas (Galli et al. 2005). Tem sido relatado que Fusarium spp. pode não reduzir a germinação de sementes, mas causa deterioração e impede o desenvolvimento radicular da plântula (Munkvold \& O'Mara 2002). Por outro lado, resultados controversos foram observados em sementes de cevada infectadas por $F$. graminearum, em que a germinação foi prejudicada e ocasionou morte de plântulas e podridão de raízes (Yang et al. 2011). Esta variação ocorreu devido a diferenças nas condições de germinação das sementes, adaptabilidade e estabilidade de cultivares, ou concentrações de macroconídios utilizados nos diferentes estudos.

$F$. graminearum e $F$. verticillioides apresentam padrões distintos, quanto à taxa de crescimento micelial e características patogênicas, em sementes e plântulas de milho, as quais podem representar risco ao estabelecimento da cultura, pela redução da germinação e emergência de plântulas (Kuhnem-Júnior et al. 2013). 
Os resultados do teste de frio de sementes de milho dos três híbridos, sem inoculação e contaminadas por $F$. verticillioides, não se ajustaram a funções polinomiais (Figura 4). Por outro lado, sementes contaminadas com $F$. graminearum apresentaram padrão distinto, no qual os resultados ajustaram-se a funções quadráticas.

Para sementes dos três híbridos de milho, com o aumento no período de exposição a $10^{\circ} \mathrm{C}$, houve ligeira redução no desempenho das sementes, avaliado pelo teste de frio. As funções do teste de frio de sementes sem inoculação e contaminadas com $F$. verticillioides assemelham-se graficamente e, assim, não mostraram diferenças no vigor (Figura 4).

Por outro lado, F. graminearum reduziu o vigor, quando as sementes de milho dos três híbridos foram expostas a períodos de até 8 dias, a $10^{\circ} \mathrm{C}$. No entanto, o desempenho foi satisfatório, quando permaneceram por 9 ou 10 dias em câmara fria. Neste caso, a hipótese é que o fungo foi inativado pelo maior período de exposição a baixas temperaturas. Assim, quando retirado da câmara fria, após períodos menores ou iguais a 8 dias, o fungo ainda estava infectivo e causou redução no vigor da amostra e influenciou no resultado do teste de frio.

Dessa forma, pressupõe-se que períodos superiores a 8 dias em câmara fria podem levar o fungo $F$. graminearum à morte, visto que as sementes mantidas por 9 ou 10 dias apresentaram melhor desempenho, igualando-se ao das sementes sadias e das sementes contaminadas por $F$. verticillioides (Figura 4).

Resultados semelhantes foram encontrados em estudos com baixas temperaturas, que reduziram a viabilidade de $F$. graminearum, em função do período de exposição, como ocorreu com sementes de triticale armazenadas em câmara fria $\left(10^{\circ} \mathrm{C}\right.$ e $30 \%$ UR) (Medina et al. 2009). Desta forma, entende-se que o fungo $F$. graminearum é afetado negativamente por baixas temperaturas da câmara fria, após período superior a 8 dias.

Na condução do teste de frio, após a permanência durante 7 dias a $10^{\circ} \mathrm{C}$, as sementes não germinam, pois, nesta temperatura, as reações que desencadeiam a germinação são reduzidas e o processo é paralisado e, assim, as sementes tornam-se mais sensíveis ao ataque de fungos (Pinto 2000).

Na situação de avaliação do vigor de lotes de sementes contaminadas por $F$. graminearum,
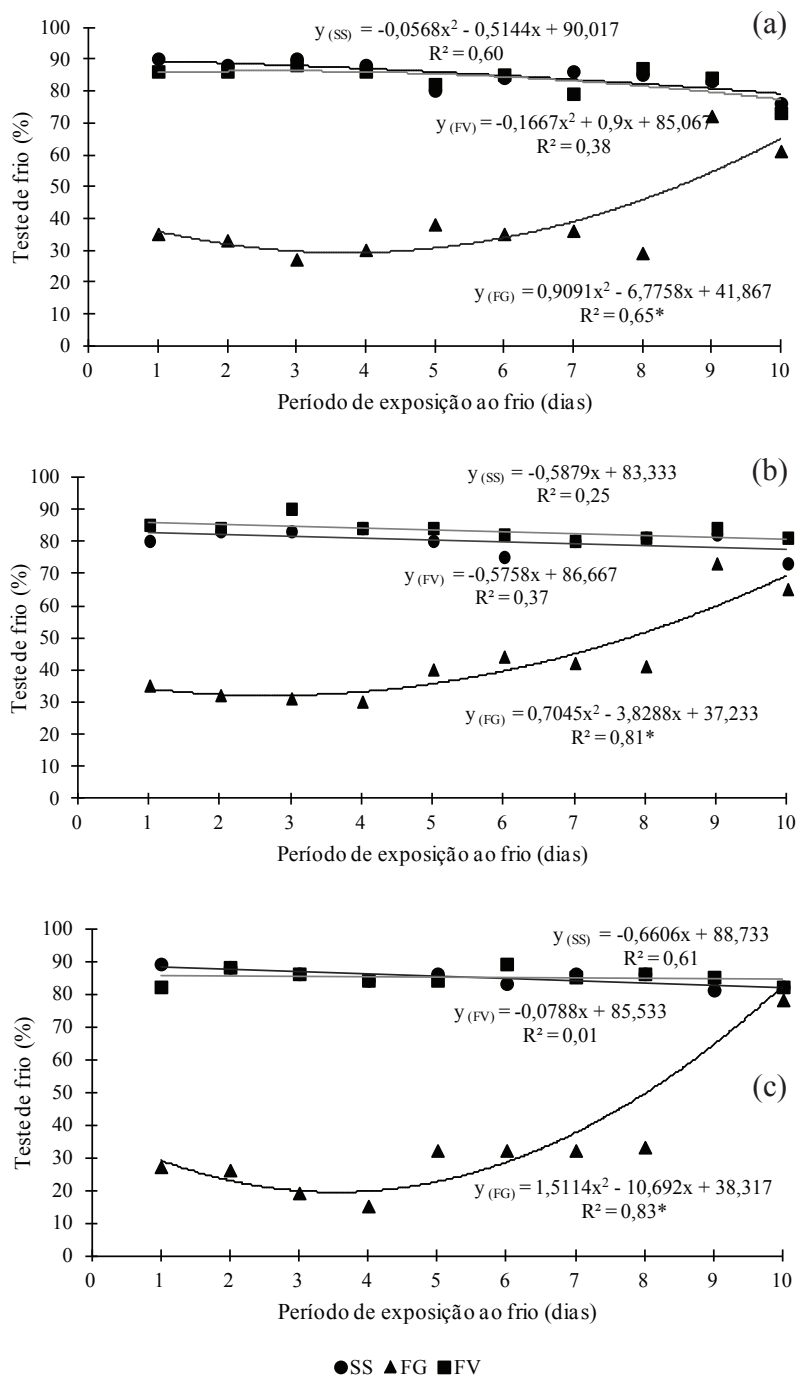

Figura 4. Vigor de sementes de milho híbrido H8480 (a), H657 (b) e $\mathrm{H} 577$ (c), quando submetidas a diferentes períodos a $10^{\circ} \mathrm{C}$, pelo teste de frio (Jaboticabal, SP, 2011). SS: sementes sadias; FG: sementes contaminadas por F. graminearum; FV: sementes contaminadas por $F$. verticillioides. $\mathrm{R}^{2}$ : coeficiente de determinação; * função polinomial significativa a $5 \%$, pelo teste $\mathrm{F}$.

por meio do teste de frio, o período de 7 dias em câmara fria, recomendado para a realização do teste (Cícero \& Vieira 1994), pode não ser adequado, pois a sobrevivência deste fungo, durante este período, pode influenciar nos resultados, reduzindo o desempenho de lotes, em função do nível de infecção.

Por outro lado, em trabalho com lotes de sementes de milho, verificou-se que, após o teste de frio conduzido a $4,5^{\circ} \mathrm{C}$, o desempenho das sementes foi superior ao do teste realizado a $10^{\circ} \mathrm{C}$ (Woltz et al. 1998). Neste caso, sugeriu-se que este resultado 
inesperado possa ser associado à menor patogenicidade de agentes presentes na terra utilizada para o teste de frio.

Alternativas para a realização do teste de frio em sementes foram propostas considerando-se equipamentos e substratos (Vieira et al. 2010), variações de temperatura (Woltz et al. 1998, Lovato et al. 2005) e períodos de exposição ao frio (Carvalho et al. 2000, Miguel et al. 2001). Estes procedimentos alternativos objetivaram viabilizar a condução do teste de frio e melhorar sua eficiência na discriminação de lotes com diferenças de vigor. Considerando-se a possibilidade de contaminação natural, seja pela terra utilizada como substrato ou pelas sementes, e para que o teste de frio mensure o potencial fisiológico destes lotes, é necessário, portanto, o prévio conhecimento da influência da qualidade fitossanitária sobre o desempenho de sementes.

\section{CONCLUSÕES}

1. O período de 16 horas de contato das sementes com Fusarium graminearum e Fusarium verticillioides foi suficiente para que os fungos infeccionassem as sementes de milho.

2. Os fungos Fusarium graminearum e Fusarium verticillioides não interferiram na germinação das sementes de milho.

3. O fungo Fusarium graminearum influenciou nos resultados do teste de frio, em sementes de milho, reduzindo o desempenho dos lotes.

\section{AGRADECIMENTOS}

Ao Conselho Nacional de Desenvolvimento Científico e Tecnológico - CNPq (Processo nº 3303321/2009-1).

\section{REFERÊNCIAS}

ALBUQUERQUE, M. C. F.; CARVALHO, N. M. Effect of the type of environmental stress on the emergence of sunflower (Helianthus annus L.), soybean (Glycine max (L.) Merril) and maize (Zea mays L.) seeds with different levels of vigor. Seed Science \& Technology, Zürich, v. 31, n. 2, p. 465-479, 2003.

ANTONELLO, L. M. et al. Qualidade de sementes de milho armazenadas em diferentes embalagens. Ciência Rural, Santa Maria, v. 39, n. 7, p. 2191-2194, 2009.

BANZATTO, D. A.; KRONKA, S. N. Experimentação agrícola. 4. ed. Jaboticabal: Funep, 2006.
BARBOSA, R. M. et al. Chemical control of pathogens and the physiological performance of peanut seeds. International Journal of Food, Agriculture and Environment, Helsinki, v. 11, n. 2, p. 322-326, 2013.

BARROS, A. S. R. et al. Teste de frio. In: KRZYZANOWSKI, F. C.; VIEIRA, R. D.; FRANÇANETO, J. B. (Eds.). Vigor de sementes: conceitos e testes. Londrina: Abrates, 1999. p. 1-15.

BRASIL. Ministério da Agricultura, Pecuária e Abastecimento. Secretaria de Defesa Agropecuária. Regras para análise de sementes. Brasília, DF: MAPA/ ACS, 2009.

BRODERS, K. D. et al. Evaluation of Fusarium graminearum associated with corn and soybean seed and seedling disease in Ohio. Plant Disease, Saint Paul, v. 91, n. 3, p. 1155-1160, 2007.

CAPPELINI, L. T. D. et al. Effect of Fusarium moniliforme on the quality of maize seeds. Cientifica, Jaboticabal, v. 33, n. 2, p. 185-191, 2005.

CARVALHO, M. A. C. et al. Variações na metodologia do teste de frio para avaliação do vigor em sementes de soja. Revista Brasileira de Sementes, Londrina, v. 22, n. 1, p. 74-80, 2000.

CÍCERO, S. M.; VIEIRA, R. D. Teste de frio. In: VIEIRA, R. D.; CARVALHO, N. M. (Eds.). Testes de vigor em sementes. Jaboticabal: Funep, 1994. p. 151-164.

COSTA, M. L. N. et al. Inoculação de Fusarium oxysporum f. sp. phaseoli em sementes de feijoeiro através de restrição hídrica. Ciência e Agrotecnologia, Uberlândia, v. 27, n. 5, p. 1023-1030, 2003.

GALLI, J. A. et al. Effect of Fusarium graminearum and infection index on germination and vigor of maize seeds. Fitopatologia Brasileira, Brasília, DF, v. 30, n. 5, p. 470474, 2005.

HENNING, F. A. et al. Qualidade sanitária de sementes de milho em diferentes estádios de maturação. Revista Brasileira de Sementes, Londrina, v. 33, n. 2, p. 316-321, 2011.

KUHNEM-JÚNIOR, P. R. et al. Características patogênicas de isolados do complexo Fusarium graminearum e de Fusarium verticillioides em sementes e plântulas de milho. Ciência Rural, Santa Maria, v. 43, n. 4, p. 583-588, 2013.

LIMONARD, T. A modified blotter test for seed health. Netherland Journal of Plant Pathology, Wageningen, v. 72, n. 2, p. 319-321, 1966.

LOVATO, A.; NOLI, E.; LOVATO, A. F. S. The relationship between three cold test temperatures, accelerated ageing test and field emergence of maize seed. Seed Science and Technology, Zürich, v. 33, n. 1, p. 249-253, 2005. 
MEDINA, P. F.; TANAKA, M. A. S.; PARISI, J. J. D. Sobrevivência de fungos associados ao potencial fisiológico de sementes de triticale ( $X$. triticosecale Wittmack) durante o armazenamento. Revista Brasileira de Sementes, Londrina, v. 31, n. 4, p. 17-26, 2009.

MIGUEL, M. H. et al. Teste de frio para avaliação do potencial fisiológico de sementes de algodão. Scientia Agricola, Piracicaba, v. 58, n. 4, p. 741-746, 2001.

MORAES, M. H. D. et al. Controle químico de Fusarium moniliforme em sementes de milho: metodologia de avaliação e efeitos sobre a qualidade fisiológica. Fitopatologia Brasileira, Brasília, DF, v. 28, n. 6, p. 626632, 2003.

MUNIZ, M. F. B. et al. Comparação entre métodos para avaliação da qualidade fisiológica e sanitária de sementes de melão. Revista Brasileira de Sementes, Pelotas, v. 26, n. 2, p. 144-149, 2004.

MUNKVOLD, G. P.; O’MARA, J. K. Laboratory and growth chamber evaluation of fungicidal seed treatments for maize seedling blight caused by Fusarium species. Plant Disease, Saint Paul, v. 86, n. 1, p. 143-150, 2002.

PINTO, N. F. J. A. Tratamento fungicida de sementes de milho contra fungos do solo e o controle de Fusarium associado às sementes. Scientia Agricola, Piracicaba, v. 57, n. 3, p. 483-486, 2000.
SARTORI, A. F.; REIS, E. M.; CASA, R. T Quantificação da transmissão de Fusarium moniliforme de sementes para plântulas de milho. Fitopatologia Brasileira, Brasília, DF, v. 29, n. 4, p. 456-458, 2004.

SOLORZANO, C. D.; MALVICK, D. K. Effects of fungicide seed treatments on germination, population, and yield of maize grown from seed infected with fungal pathogens. Field Crops Research, Amsterdam, v. 122, n. 1, p. 173-178, 2011.

VIEIRA, B. G. T. L. et al. Alternative procedure for the cold test for soybean seeds. Scientia Agricola, Piracicaba, v. 67, n. 5 , p. $540-545,2010$.

WOLTZ, J. M. et al. Corn cold test germination as influenced by soil moisture, temperature and pathogens. Seed Technology, Ithaca, v. 20, n. 1, p. 56-70, 1998.

YANG, F.; SVENSSON, B.; FINNIE, C. Response of germinating barley seeds to Fusarium graminearum: the first molecular insight into Fusarium seedling blight. Plant Physiology and Biochemistry, Versailles, v. 49, n. 2, p. 1362-1368, 2011.

YATES, I. E. et al. Field performance of maize grown from Fusarium verticillioides inoculated seed. Mycopathologia, Berlin, v. 159, n. 1, p. 65-73, 2005. 